\title{
Uma Breve Revisão Sobre A Potencialidade De Utilização De Células Combustíveis Microbianas Para O Tratamento De Resíduos Da Indústria De Laticínios
}

\author{
Eduarda Valéria de Freitas Morais* (Aluna do Curso Técnico e Integrado em Biocombustíveis no Instituto \\ Federal do Rio Grande do Norte - IFRN). \\ Hanniel Ferreira Sarmento de Freitas; (Professor no Instituto Federal do Rio Grande do Norte - IFRN). \\ *eduardavaleria_@hotmail.com
}

\begin{abstract}
resumo
O presente estudo procura explorar o que se relaciona com os efluentes provenientes da indústria de laticínios, o tratamento desses resíduos e como ele pode ser feito usando células combustíveis microbianas (CCM) para que assim, a problemática do esgotamento das fontes de energia fósseis seja resolvida ou, pelo menos, incentive o estudo dessa fonte energética que pode ser utilizada em longo prazo. Além disso, explana a ideia de produzir efluentes sintéticos análogos aos resíduos liberados pela indústria láctica diariamente e avalia, por fim, os resultados que cada pesquisador obteve ao tratar essas águas sintéticas residuais. Nesse sentido, os melhores resultados presentes na literatura consultada reportam uma densidade de potência de 3,2 $\pm 0,3 \mathrm{~W} / \mathrm{m}^{3}$ aliados a uma remoção máxima de DQO de $80 \%$, valores que enfatizam a importância da utilização das CCM como uma alternativa para a geração energética em paralelo com a remediação de efluentes industriais.
\end{abstract}

PALAVRAS-CHAVE: Células combustíveis microbianas; Energia renovável; Remediação de efluentes; Biotecnologia

\section{A BRIEF REVI EW OF THE POTENTI AL OF MI CROBI AL FUEL CELLS FOR WASTE TREATMENT OF DAI RY I NDUSTRY}

\begin{abstract}
This study explores what relates to the effluent from the dairy industry, improved waste treatment and how it can be done using microbial fuel cells (CCM) so that the problem of the exhaustion of fossil energy sources is resolved or at least encourage the study of such energy source that can be used in the long term. Furthermore, explains the idea of producing synthetic analogues to the waste effluents released by dairy industry evaluated daily and, finally, the results obtained by each searcher treat these waste synthetic water. In this sense, the best results present in the literature report a power density of $3.2 \pm 0.3 \mathrm{~W} / \mathrm{m}^{3}$ combined with a maximum COD removal of $80 \%$, values that emphasize the importance of using CCM as an alternative to energy generation in parallel with the remediation of industrial effluents.
\end{abstract}

KEYWORDS: Microbial Fuel Cells; Renewable Energy; Effluent remediation; Biotechnology

\section{1. introdução}


Até o século XIX as fontes usuais de energia eram obtidas diretamente da natureza. O sol, a força dos ventos, da água e dos animais dominava o cenário energético mundial, porém quando a Revolução Industrial teve início, o uso do carvão e da madeira, e mais tarde com a descoberta e retirada do petróleo, ganharam impulso e passaram a ser utilizados de forma excessiva. Face ao franco ritmo de expansão da sociedade moderna, com a demanda crescente por energia para seu desenvolvimento, diversos estudos têm sido realizados e que apontam para o esgotamento futuro dos combustíveis fósseis, a fonte mais utilizada para a geração energética mundial. Tem sido fomentado então o interesse por novas fontes de energia, a exemplo da utilização de placas fotovoltaicas, energia eólica, células combustíveis microbianas (CCM), e diversas outras, sendo esta última o foco deste trabalho.

Os primeiros relatos referentes às CCM rementem do século XVIII, quando Luigi Galvani notou a contração das pernas de uma rã ao submetê-las à descarga de corrente elétrica. Séculos depois, em 1911, Potter demonstrou que bactérias E. Coli liberavam energia depois de atuarem sobre um substrato orgânico. Vinte anos depois, Cohen retomou a ideia, provando que as CCM podiam fornecer uma tensão de aproximadamente 35 Volts e corrente elétrica de $2 \mathrm{~mA}$. Durante muito tempo nada mais se falou sobre as células, elas não passavam de uma curiosidade científica, somente em 1960 elas voltarem a ser discutidas, quando a NASA demonstrou interesse em estudá-las. Muitas pesquisas iniciais foram feitas, com diferentes tipos de bactérias e substratos que serviam de combustíveis para a célula (RACHINSKI, 2010).

Com o desenvolvimento de novas pesquisas as condições a que as células eram submetidas, como temperatura e substrato, foram sendo alterados para favorecem os resultados de tensão, corrente e eficiência. Substratos como glicose e acetato se tornaram ultrapassados quando surgiu a possibilidade de usar a biomassa de resíduos ou tratamento das águas residuais para melhorar a produção de energia nas CCM, segundo Pant et al. (2009). Entretanto, efluentes da indústria de cervejaria e de cana-de-açúcar, soro de leite, resíduos de matadouros e água residuária de conservas de frutas e legumes também têm grande potencial na geração de energia.

Segundo Silva (2011), a indústria de laticínios gera vários tipos de resíduos, estes que são capazes de causar grandes impactos ao meio ambiente, sejam em suas formas líquida, sólida ou gasosa. Os efluentes dessa indústria são considerados um dos principais responsáveis pela poluição. "Nas indústrias de laticínios qualquer etapa do processamento gera grandes volumes de resíduos, as chamadas "águas brancas”, devido ao processo de higienização. A água desse processo contém produtos lácteos diluídos que contribuem para as perdas de leite e para a produção total do efluente.” (BALLANEC et al., 2002 apud BRUM, SANTOS JÚNIOR, BENEDETTIC, 2009). "Independente do tamanho e potencial poluidor da indústria, a legislação ambiental exige que todas as empresas tratem e disponham de forma adequada seus resíduos." (SILVA, 2011). Sabendo disso torna-se viável fazer o controle ambiental e minimizar ao máximo a produção desses resíduos, e ainda encontrar uma forma de reciclar esses resíduos reduzindo os custos com tratamentos e disposição final.

No presente trabalho tem-se como objetivo explorar a problemática dos efluentes da indústria de laticínios, além do uso desses resíduos em células combustíveis microbianos, atentando para os resultados obtidos nas pesquisas realizadas na comunidade científica.

\section{METODOLOGIA}

\subsection{CÉLULAS COMBUSTí VEIS MI CROBI ANAS}

As células combustíveis são dispositivos relativamente novos e que ainda estão em fase de pesquisa. Alguns modelos já estiveram disponíveis no mercado, mas logo desapareceram, decorrente da baixa aceitação (MARCON, et al. 2012). Lehnen (2014) explica que:

"As células de combustível microbianas emergiram recentemente como uma tecnologia promissora, porém ainda desafiadora. Há a necessidade de um melhor entendimento do mecanismo envolvido na conversão da energia bioeletroquímica, na transferência de elétrons e nos processos de biotransformação para que as limitações hoje apresentadas por esses sistemas sejam sanadas possibilitando o desenvolvimento de plantas com maior eficiência.” (LEHEN, 2014, p.01)

As CCM são aparatos semelhantes a pilhas eletroquímicas. Nas palavras de Marcon et al. (2012), CCM é um aparato que, espontaneamente, converte substratos orgânicos em eletricidade através da atividade metabólica dos microorganismos, ou seja, os microorganismos interagem com os eletrodos e liberam elétrons, que ao entrarem em movimento formam a corrente elétrica. Na CCM os elétrons que são gerados atravessam o condutor elétrico até chegar ao cátodo onde ocorre a redução do composto presente no 
compartimento. Enquanto isso, no ânodo os prótons que são gerados migram até o cátodo através de uma membrana semipermeável que separa os dois compartimentos, estabelecendo-se uma diferença de potencial entre os dois eletrodos. (LEHNEN, 2014.)

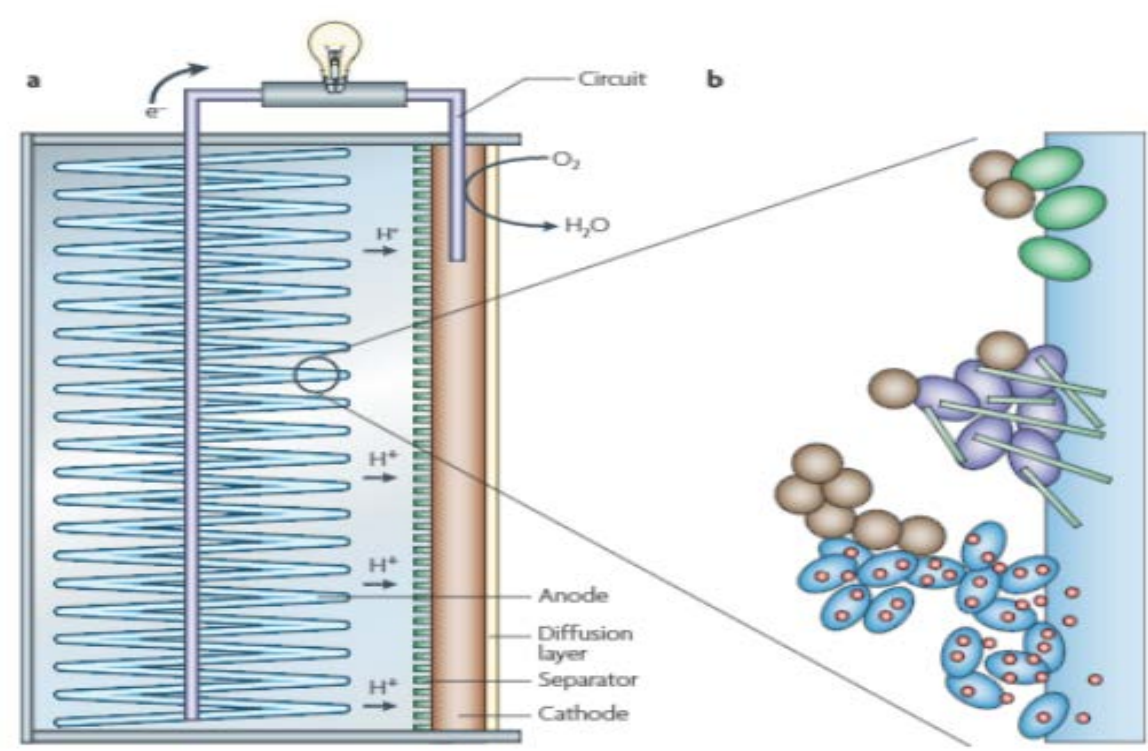

Figura 1: Esquema de uma CCM. Fonte: Logan (2009).

Os materiais usados para construir o cátodo e o ânodo devem ter características específicas, como Lehnen (2014) expôs em seu trabalho. O do cátodo deve possuir alto potencial redox e ser fácil de capturar prótons, e do ânodo baixa resistência e condutividade elétrica, alta biocompatibilidade, estabilidade química e não pode sofrer corrosão.

Existem vários tipos e geometrias diferentes de CCM, embora a opinião sobre esses aspectos variem de autor para autor. Pesquisadores como Lehnen (2014), Rachinski (2010), Peixoto et al. (2013) apresentaram em seus trabalhos algumas dessas configurações. Lehnen (2014) opina que o que diferencia as células é a natureza e mecanismo da troca de elétrons, além da quantidade de compartimentos, o tipo e tamanho de eletrodos, substratos etc. É possível observar a configuração em formato de H, citada por Lehnen (2014), a seguir.

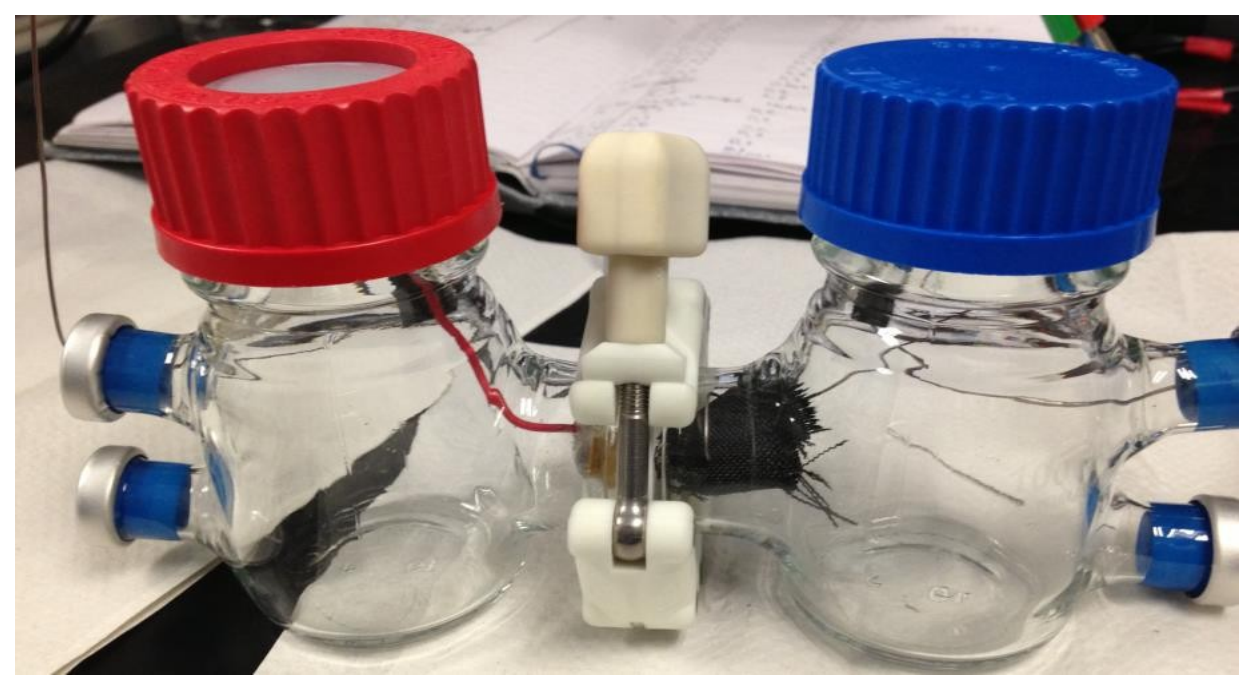

Figura 2: Tipo de CCM em formato de H. Fonte: Lehnen (2014).

Já Rachinski (2010) informa que existem quatro principais configurações para as CCM, estas são: (I) MFC de Biorreator Desacoplado. Há produção microbiológica de hidrogênio ou metano, com subsequente recuperação em um biorreator separado procedido por uma célula de combustível química, geralmente operando a altas temperaturas, para converter o gás hidrogênio em eletricidade. II) MFC de Biorreator Integrado. Há produção microbiológica de hidrogênio e conversão em eletricidade em apenas uma célula. III) 
MFC com transferência direta de elétrons. Há geração de eletricidade com o uso de microrganismos e transferência direta do elétron para o ânodo. IV) MFC com mediador para a transferência de elétrons. Há geração de eletricidade através dos micro-organismos e transferência do elétron para o ânodo por meio de um "carregador" de elétrons funcionando como mediador. (RACHINSKI, 2010, p. 13)

Peixoto et al. (2013) vem com a ideia de três configurações básicas. A primeira corresponde a um reator em forma de $\mathrm{H}$, constituído por duas câmaras e uma membrana de troca de prótons (MTP). Pensando em diminuir a distancia entre os eletrodos desenvolveram reatores cilíndricos que permite uma maior troca de prótons. E por último, a CCM submersível onde o cátodo mantém contato direto e contínuo com o ar, e o ânodo é um reator anaeróbio. Há muitos trabalhos documentados na comunidade científica sobre as células combustíveis, realizados com substratos e condições diferentes. A alteração dessas variáveis influencia de forma abrupta nos resultados de potência, tensão e corrente. No Quadro 1 é possível ver a alteração da potência máxima a cada mudança de substrato, temperatura e o tipo de CCM.

Quadro 1 - Resultados de Potência Máxima obtidos em trabalhos da comunidade científica. 


\section{LATICÍNIOS}

De acordo com a literatura consultada, o efluente gerado na higienização do leite é composta de um licor rico em gorduras, carboidratos (lactose, principalmente) e proteínas (caseínas, principalmente) que passam a ser contaminantes se lançado in natura no meio ambiente (PEIRANO, 1995 apud BRUM et al. 2009). Segundo Kispergher (2013) "os efluentes de laticínios são compostos por quantidades variáveis de leite diluído, materiais sólidos flutuantes originados de diversas fontes, como detergentes, desinfetantes, lubrificantes e esgoto doméstico.”. Ainda segundo o autor:

“As indústrias de produtos lácteos, em especial os fabricantes de queijos, geram efluente com elevada carga orgânica. Esses efluentes são compostos por quantidades variáveis de resíduo de leite e materiais sólidos flutuantes originados de diversas fontes. A quantidade de carga poluente das águas residuais das indústrias de laticínios varia bastante, dependendo da quantidade de água utilizada, do tipo de processo e do controle exercido sobre as várias descargas de resíduos.” (NIRENBERG, 2005 apud KISPERGHER, 2013, p. 15.)

Segundo Moreira (2007) apud Santos et al (2009), o lançamento dos efluentes provenientes da indústria de laticínios, sem qualquer tipo de tratamento prévio, nos corpos hídricos, gera diversos impactos ambientais como a elevação da demanda química de oxigênio (DQO) da água, diminuindo a quantidade oxigênio dissolvido na água; alteração da temperatura; aumento da concentração de sólidos solúveis; eutrofização dos corpos hídricos e proliferação de doenças veiculadas pela água etc.

Existem alguns trabalhos em que foram produzidos e utilizados efluentes sintéticos similares a resíduos da indústria de laticínios. Como o trabalho de Kispergher (2013), em que ele utilizou na composição do seu efluente 5 g. $\mathrm{L}^{-1}$ de leite em pó integral e para em outro momento ainda adicionou 4 g.L ${ }^{-1}$. Houve essa escolha de utilizar um efluente sintético devido a facilidade de acesso e padronização das operações, além de pode ser preparado diariamente sem implicar em possíveis contaminações. Já no trabalho de Brião (2005) utilizou-se $17 \mathrm{~g}$ de leite em pó integral em $10 \mathrm{~L}$ de água, de modo que a demanda química de oxigênio permaneceu na faixa de $2000 \mathrm{mg} \mathrm{L}^{-1}$ a $2500 \mathrm{mg} \mathrm{L}^{-1}$, simulando a concentração de um efluente industrial. Por outro lado, no trabalho de Silva (2013) a água residuária teve uma composição bastante diferente, pois era composta tanto de macro como micronutrientes, foram utilizados os seguintes compostos nas seguintes concentrações:

Tabela 1: Composição da água redisuária de Silva (2013).

\begin{tabular}{c|c}
\hline Composição & Concentração \\
\hline Leite em pó integral & $28,8 \mathrm{~g}$ \\
\hline$\left(\mathrm{NH}_{2}\right)_{2} \mathrm{CO}$ & $54 \mathrm{~g}$ \\
\hline $\mathrm{NH}_{4} \mathrm{Cl}$ & $11,67 \mathrm{~g}$ \\
\hline $\mathrm{NaH}_{2} \mathrm{PO}_{4} \cdot \mathrm{H}_{2} \mathrm{O}$ & $18 \mathrm{~g}$ \\
\hline $\mathrm{K}_{2} \mathrm{CO}_{3}$ & $12 \mathrm{~g}$ \\
\hline $\mathrm{NaHCO}_{3}$ & $31,2 \mathrm{~g}$ \\
\hline $\mathrm{MgSO}_{4} \cdot 7 \mathrm{H}_{2} \mathrm{O}$ & $12 \mathrm{~g}$ \\
\hline $\mathrm{FeSO}_{4} \cdot 7 \mathrm{H}_{2} \mathrm{O}$ & $0,480 \mathrm{mg}$ \\
\hline $\mathrm{MnSO}_{4} \cdot \mathrm{H}_{2} \mathrm{O}$ & $0,480 \mathrm{mg}$ \\
\hline $\mathrm{CaCl}_{2} \cdot 2 \mathrm{H}_{2} \mathrm{O}$ & $0,720 \mathrm{mg}$ \\
\hline Água de torneira & $20 \mathrm{~L}$ \\
\hline
\end{tabular}

\section{RESULTADOS APRESENTADOS NA LITERATURA}

Analisando os resultados dos efluentes produzidos pelos autores citados no tópico anterior é possível ver os seguintes resultados. No trabalho de Kispergher (2013), houve uma remoção de DQO de 56,6\%, enquanto no de Brião (2005) ficou na faixa de $65 \%$ a $76 \%$, e no estudo de Silva (2013) $71,1 \%$, vale lembrar que em nenhum desses trabalhos foram medidos a corrente ou tensão produzidos, mas indicam ter um grande potencial no tratamento de efluentes. Por outro lado, no trabalho de Kelly (2013), que não houve o uso de 
efluentes sintéticos, apenas de diferentes substratos da indústria láctica em 4 CCM diferentes, a densidade de potência máxima chegou a 3,2 $\pm 0,3 \mathrm{~W} / \mathrm{m}^{3}$, e o maior percentual de eficiência de Coulomb foi de $27,2 \pm$ $3,6 \%$, enquanto a remoção de DQO máxima foi de $80 \%$.

\section{CONSI DERAÇÕES FINAIS}

O esgotamento das atuais formas de energia vem se tornando uma preocupação frequente, e encontrar uma solução para o problema é, claramente, um grande desafio para a comunidade científica, porém com popularização das CCM e com a possibilidade de utilizar nelas efluentes dos mais variados tipos, inclusive da indústria de laticínios (esta que despeja grandes quantidades de resíduos diariamente), para gerar energia pode-se dizer que esse problema seria minimizado.

Por fim, sobre o uso dos efluentes sintéticos análogos é possível notar que ainda há poucos trabalhos em andamentos do uso desses resíduos em CCM, porém de acordo com os trabalhos listados as pesquisas seguem um caminho aparentemente desejável.

\section{REFERÊNCI AS}

BRIÃO, V., B., TAVARES, C., R., G., CALEFFI, R., D., Ultrafiltração para o tratamento de efluentes de laticínios. In: $23^{\circ}$ Congresso Brasileiro de Engenharia Sanitária e Ambiental, 2005, Campo Grande.

BRUM, L. F. W., SANTOS JÚNIOR, L. C. O., BENEDETTIC, S., Reaproveitamento de Água de Processo e Resíduos da Indústria de Laticínios. In: 2nd International Workshop | Advances in Cleaner Production, São Paulo, 2009.

JOHN, A. M. S., LOPES, B. C. V. Acompanhamento da geração de potencial elétrico por célula combustível microbiana. Monografia (Curso Superior de Tecnologia em Processos Ambientais), Universidade Federal Técnica do Paraná, Curitiba. 2013.

KISPERGHER, E., M, Digestão anaeróbia de efluentes da indústria de alimentos. Dissertação (Mestrado em Engenharia de Alimentos) - Universidade do Paraná, Curitiba, 2013.

LEHNEN, D. R. 2014. Desenvolvimento de células de combustível microbianas. Dissertação (Mestrado em Química) - Universidade Federal do Rio Grande do Sul, Porto Alegre, 2014.

LOGAN, B.E., Exoelectrogenic bacteria that power microbial fuel cells. Nat. Rev. Microbiol. 7 (2009), 375-381

KELLY, P., T., Investigation of application niche for sustainable wastewater treatment using microbial fuel cells. 2013. University of Wisconsin Milwaukee. UWM Digital Commons. Theses and Dissertations. Paper 594.

MARCON, L. R. C.; MARQUES, A. F.; DANIEL, L. A. Emprego de células combustíveis microbianas na geração de energia elétrica. In: III Fórum Brasileiro de Energia, 2012, Foz do Iguaçu.

MARCON, L. R. C. Potencialidade da célula combustível microbiana para geração de energia elétrica a partir de esgoto sanitário. 2011. Dissertação (Mestrado em Hidráulica e Saneamento) - Escola de Engenharia de São Carlos, Universidade de São Paulo, São Carlos. 2011.

MARQUES, A. F. Células combustíveis microbianas aplicadas ao tratamento de efluentes. 2014. Monografia, Escola de Engenharia de São Carlos, Universidade de São Paulo, São Carlos, 2014.

PANT D.; BOGAERT G. Van.; DIELS L.; VANBROEKHOVEN K. A review of the substrates used in microbial fuel cells (MFCs) for sustainable energy production. Bioresource Technology, v. 101, n. 6, p. 
PEIXOTO, L., MARTINS, G. , AMORIM, D., PARPOT, P., NOGUEIRA R. e BRITO, A. G. de. Células de combustível microbianas: um processo inovador para produção de energia e tratamento de águas residuais em sistemas descentralizados. in: $11^{\circ}$ Simpósio de Hidráulica e Recursos Hídricos dos Países de Expressão Portuguesa e VII Congresso sobre Planejamento e Gestão de Zonas Costeiras dos Países de Expressão Portuguesa, 2013, Maputo, Moçambique.

RACHINSKI, S. Uso de subprodutos da indústria agropecuária na geração de energia elétrica através de células combustíveis microbianas. Dissertação (Mestrado em Química) - Universidade Federal do Paraná, Curitiba. 2010.

SANTOS, A., M., dos., SILVA, S., R., da., CARVALHO, S., H., V., de, SOLETTI, J., I., Tratamento de efluentes lácteos através de coagulação química e sedimentação. In: $8^{\circ}$ Congresso Brasileiro de Engenharia Química em Iniciação Científica, 2009, Uberlândia, Minas Gerais, Brasil.

SILVA, D., J., P., da. Resíduos na indústria de laticínios. Departamento de Tecnologia de Alimentos. Universidade Federal de Viçosa. Rio de Janeiro. 2011.

SILVA, L., V., C., ANDRADE, M., V., RODRIGUES, K., MARINHO, G., Tratamento de efluente sintético de laticínio em reatores em batelada inoculados com Aspergillus Niger AN400. Eng Sanit Ambient, v.18 n.4, out/dez 2013, p. 371-380. 